\title{
How alcohol industry organisations mislead the public about alcohol and cancer
}

Mark Petticrew $\mathrm{PhD},{ }^{1 *}$ Nason Maani Hessari $\mathrm{PhD},{ }^{1}$ Cécile Knai $\mathrm{PhD},{ }^{1}$ Elisabete Weiderpass $\mathrm{MD} \mathrm{PhD}{ }^{2}$

1. Faculty of Public Health and Policy, London School of Hygiene and Tropical Medicine, 15-17 Tavistock Place, London WC1H 9SH

2. Department of Medical Epidemiology and Biostatistics, Karolinska Institutet, Nobels väg 12A 17177 Stockholm, Sweden.

* Corresponding author: Mark.Petticrew@1shtm.ac.uk

This is the peer reviewed version of the following article:

Petticrew M, Maani Hessari N, Knai C, Weiderpass E. How alcohol industry organisations mislead the public about alcohol and cancer. Drug and Alcohol Review (March 2018), 37, 293-303

which has been published in final form at: https://onlinelibrary.wiley.com/doi/abs/10.1111/dar.12596 DOI: 10.1111/dar.12596

This article may be used for non-commercial purposes in accordance with Wiley Terms and Conditions for Use of Self-Archived Versions. 


\section{Abstract [249 words]}

Introduction: Alcohol consumption increases the risk of several types of cancer, including several common cancers. As part of their corporate social responsibility activities the alcohol industry (AI) disseminates information about alcohol and cancer. We examined the information on this which the AI disseminates to the public through its "social aspects and public relations organizations" (SAPROs), and related bodies. The aim of the study was to determine its comprehensiveness and accuracy.

Design and Methods: Qualitative analysis of websites and documents from 27 alcohol industry organisations. All text relating to cancer was extracted and analysed thematically.

Results: Most of the organisations were found to disseminate misrepresentations of the evidence about the association between alcohol and cancer. Three main industry strategies were identified: (1) Denial/omission: Denying, omitting or disputing the evidence that alcohol consumption increases cancer risk; (2) Distortion: Mentioning cancer, but misrepresenting the risk; and (3) Distraction: focussing discussion away from the independent effects of alcohol on common cancers. Breast cancer and colorectal cancer appeared to be a particular focus for this misrepresentation.

Discussion and Conclusions: The alcohol industry appears to be engaged in the extensive misrepresentation of evidence about the alcohol-related risk of cancer. These activities have parallels with those of the tobacco industry. This finding is important because the industry is involved in developing alcohol policy in many countries, and in disseminating health information to the public, including schoolchildren. Policymakers, academics, public health and other practitioners should reconsider the appropriateness of their relationships to these alcohol industry bodies.

Keywords: alcohol; public health; cancer; corporate influences 


\section{Introduction}

Alcohol consumption is a well-established risk factor for a range of cancers, accounting for about $4 \%$ new cancer cases annually.[1 2] The evidence of an association has been clear since the 1988 review by the International Agency for Research on Cancer (IARC), which reported an increased risk of oral cavity, pharynx, larynx, oesophagus, and liver cancers.[3] In 2007, as more evidence became available, IARC added breast cancer and colorectal cancer to the list.[4] Since then the evidence has strengthened further, with at least 100 studies on alcohol and breast cancer alone,[5] and the most comprehensive review of the evidence to date shows that the risk of breast cancer is increased even at low levels of consumption.[6] Both the most recent IARC review in 2012 [7] and the UK's Committee on Carcinogenicity (CoC) review in 2016[8] confirmed the increased risks of cancers of the mouth and throat, larynx, oesophagus, upper aerodigestive tract, breast, liver, colon and rectum, and pancreas (see Supplementary Table 1). There is little evidence of an association with ovarian and prostate cancer, though a recent meta-analysis has reported an increased risk of prostate cancer.[9] The evidence on other cancers remains unclear.[7] The $\mathrm{CoC}$ concluded that the evidence that alcohol consumption reduces the risk of some cancers (including renal cell cancers, and cancers of the kidney, ovary, thyroid, and lung) remains limited and inconsistent, and that the increased risk of other cancers as a result of drinking alcohol far outweighs any possible decreased risk.[8] The weight of scientific evidence is therefore clear that drinking increases the risk of some of the most common cancers.[10]

The relationship between alcohol consumption and cancer has been disputed by the alcohol industry (AI) and its affiliated organisations.[11] At the same time many AI-funded organisations, most commonly "social aspects and public relations organizations" (SAPROs), disseminate health information with the stated intention of informing consumers and encouraging "responsible drinking". [12] Such organisations are portrayed as delivering on the AI's corporate social responsibility (CSR) goals, but it has been argued that these organisations activities are in fact aimed at maintaining profits 
by promoting ineffective interventions, misrepresenting the evidence, and attempting to influence public perceptions.[12]

This study analysed the information on cancer which is disseminated by alcohol industry SAPROs and similar organizations. We aimed to determine the extent to which they fully and accurately communicate the scientific evidence on alcohol and cancer to consumers.

\section{Methods}

We searched for information on cancer and alcohol consumption disseminated by 27 alcohol industry bodies, and related organisations (See Table 1, and Supplementary Table 2). These were identified during September-December 2016 from the Global Alcohol Producers website and its progress reports, and from the Corporate Social Responsibility (CSR) sections of alcohol producers' websites. [13 14] We included organisations from English speaking countries or where the information was available in English. One website was inaccessible, leaving 26 for analysis.

Two authors independently extracted information from documents, webpages or reports. These data were coded iteratively by two authors in Excel and in nVivo 11.3.2, and were analysed using documentary analysis methods.[15] [16] The approach comprised reading and understanding meanings of individual texts to identify sub-themes; identification of thematic clusters of nodes; triangulation between documents and organisations; checking reliability/validity, and the use of representative examples.[17] [18] [19] Disagreements about coding, or relevance were referred to a third author. This resulted in 15 codes which were grouped for analysis into three main industry strategies (see Box 1 below). The quotes were coded independently by two authors, and agreement calculated using the $\kappa$ statistic $(\kappa=0.4)$. All the data were extracted by one author, then a second author then went back to the same sources to check all data, before the final coding took place. 
The detailed information on cancer presented by these organisations is included as supplementary material online (Supplementary Table S2). Representative examples are given below to highlight the common approaches used by these organisations. Additional examples appear in Supplementary Table S3.

Ethic approval: Ethical approval not required (secondary document analysis).

\section{Results}

Most organizational websites (24/26) contain significant omissions and/or misrepresentations of the evidence. They appear to use three main strategies (Box 1). 
Box 1: How the alcohol industry organisations under review misrepresent the evidence on alcohol and cancer

1. Denial/omission: denying, or disputing any link with cancer, or selective omission of the relationship

The approach includes:

- Denying that any relationship exists, or claiming inaccurately that there is no risk for light or "moderate" drinking; and

- Selective omission: avoiding mention of cancer in general, or of specific cancers

2. Distortion: mentioning some risk of cancer, but misrepresenting or obfuscating the nature or size of that risk

This is done by:

- Claiming or implying that the risk applies only to particular patterns of drinking (heavy drinking, or binge drinking);

- Claiming or implying that, as knowledge of the mechanism is incomplete, the evidence of a causal relationship is not trustworthy; and/or claiming a lack of expert consensus.

- Claiming protective effects of alcohol on some cancers, thus confusing the picture of overall risk.

3. Distraction: focussing discussion away from the independent effects of alcohol on common cancers

This is done by:

- Minimising the role of alcohol by pointing to a wide range of other risk factors for cancer; and

- Emphasising less common cancers, and emphasising cancer "types" rather than cancer prevalence;

In addition, there appears to be a focus on misrepresenting the risks of breast, and colorectal cancer.

1. Denying, disputing, or selectively omitting the relationship between alcohol consumption and cancer

1(i) Denying that any relationship exists or claiming inaccurately that there is no risk for light or 'moderate' drinking

As noted in Supplementary Table 1, alcohol consumption is associated with at least seven types of cancer.[20] Five AI organisations deny an association between alcohol and at least one type of cancer 
with statements which are contradicted by the existing evidence (Table 1). A frequent approach is to present misleading information about the risk associated with "light" or "moderate" drinking, as in these examples:

"Recent research suggests that light to moderate drinking is not significantly associated with an increased risk for total cancer in either men or women" (International Alliance for Responsible Drinking (IARD)[21]

"Some studies show a link between alcohol and breast cancer among both pre-menopausal and post-menopausal women. However, no causal relationship has been shown between moderate drinking and breast cancer.” Éduc'alcool (Quebec)[22]

The first statement from IARD (International Alliance for Responsible Drinking, an alcohol producers 'responsible drinking' body) misrepresents the well-evidenced association between alcohol consumption and a range of specific, common cancers. The second statement from Éduc'alcool about 'no causal relationship' is factually incorrect.

An informational video about cancer on the SAB Miller website 'TalkingAlcohol.com' similarly states inaccurately that there is no link between alcohol and most cancers except for "mainly cancers of the upper aerodigestive tract" and the liver.[23] (Other examples: see Supplementary Table S3).

1(ii) Selective omission: avoiding mention of cancer, and/ or of specific cancers

Most of the websites or documents (13/21 from SAPROs and 5/5 from producers) either do not mention cancer (while discussing other health risks) or appear to selectively omit specific cancers (Table 1). For example, Pernod's 'Wise Drinking' brochure discusses the need to "combat unhealthy drinking habits", and lists "mental retardation in children" as among the most common consequences of alcohol consumption, but presents no information on cancer.[24] Diageo's DrinkIQ.com website has a section entitled "Alcohol's short-term and long-term effects on your body", listing alcohol 
dependence, pancreatic problems, liver cirrhosis, brain damage, death and "physical and emotional health problems".[25] It does not mention cancer. Educ'alcool (Quebec) has a webpage labelled “The effects of moderate, regular alcohol consumption", which mentions cardiovascular and peripheral disease, stroke, gallstones, diabetes, psychosocial effects and 'other beneficial effects', but does not mention cancer. [22]

\section{Distortion: mentioning some risk of cancer, but obscuring, misrepresenting or obfuscating the}

\section{nature or size of that risk}

The second and most common approach involves presenting the relationship between alcohol and cancer as highly complex (for example, in terms of subgroup effects, and patterns of drinking), with the implication, or statement, that there is no evidence of a consistent, or independent link. Within this, three approaches were identified (see also Supplementary Table S3):

2(i) Claiming or implying that risk only applies to particular patterns of drinking

It is commonly stated by these organisations (12/20 SAPROs) that the risk of some common cancers only exists for "heavy", "excessive" or "binge" drinking. For example,

Cancer risk associated with the consumption of alcohol is related to patterns of drinking, particularly heavy drinking over extended periods of time (Australia, Drinkwise[26]).

Similar statements also appear on the IARD website, such as "In general, alcohol-associated cancers have been linked with heavy drinking” (IARD)[27]

The scientific evidence suggests that such statements are misleading (Supplementary Table 1), because the increased risk of some common cancers, such as breast, oesophageal, laryngeal, mouth 
and throat cancers, and cancers of the upper aero-digestive tract, starts at low levels of consumption, even though it is low at those low levels.[7] [8] (See also Supplementary Table S3).

2 (ii) Claiming or implying that, as knowledge of the mechanism is incomplete, the evidence of a causal relationship is not trustworthy; and/or claiming a lack of expert consensus

Other industry claims (from three organisations) relate to disputation of the mechanisms, or involve claims about the consistency of the evidence, as in these examples:

"Recent studies indicate a dose-response relationship between alcohol consumption and breast cancer, although this relationship was not evident in some past studies"(IARD).[27]

"All the studies show that the knowledge about the causes of breast cancer is still very incomplete and as scientists from the National Institute on Alcohol Abuse and Alcoholism in the USA recently pointed out, some other (possible confounding) factors have not been considered in the research relating the consumption of alcoholic beverages to breast cancer" (Wine Information Council).[28]

This is also a feature of SABMiller materials: "The mechanism by which alcohol consumption may cause breast cancer is not fully known.... The relationship... is undergoing vigorous research... If and how these two factors may interact and affect risk is not completely known". (Supplementary Table S2)

2 (iii) Claiming protective effects of alcohol on some cancers, thus confusing the picture of overall risk. 
The evidence that cancer reduces the risk of some cancers is very limited. The Committee on Carcinogenicity review of 2016 stated in relation to protective effects:

"We think that it is difficult to draw firm conclusions from a small number of studies that indicate that kidney cancer, non-Hodgkin lymphoma [NHL], Hodgkin lymphoma [HL], and extra-hepatic bile system cancer are less common in people who drink alcohol than in nondrinkers. However, it is clear that the increased risk of other cancers as a result of drinking alcohol far outweighs any possible decreased risk of these cancers".,[8]

In relation to NHL and HL, the Committee on Carcinogenicity also stated in their review of the evidence that they "....have concerns about the consistency of the classification of cancers of this type and the confounding effect of diverse lymphoma types. In addition, there is no immediately obvious mode of action that could explain the association".[8]

Despite the lack of evidence for protective effects of alcohol consumption on cancer, a wide range of protective effects are claimed in industry websites. For example ARA, a South African SAPRO,[29] and the industry body IARD,[27] state that there is a protective effect for renal cell cancer, and nonHodgkin lymphoma. IARD also appears to claim a protective effect against multiple myeloma, while at the same time acknowledging that the findings from individual studies are inconsistent.[27] The IARD conclusion regarding an inverse risk of non-Hodgkin lymphoma is consistent with the IARC report in 2012.[7] The IARD conclusion regarding multiple myeloma is not in agreement with that of IARC, who reported no consistent association with multiple myeloma in most studies.[7]

The Wine Information Council claims that:

"Moderate wine intake may actually reduce the risk of oesophagus, thyroid, lung, kidney and colorectal cancers as well as Non-Hodgkin's Lymphoma. ...Concerning breast cancer, there may also be a protective role for wine." (Wine Information Council)[30] 
Claims about the protective effects are also made on the SABMiller website, which states that moderate alcohol consumption can be linked to lower risk of bladder, kidney, ovarian and prostate cancer. [31] IARD also appears to recommend drinking as protective in smokers:

"Among long-term smokers consumption of alcohol has been shown to be protective against colorectal adenomas".[27]

The Portman Group's response to the consultation on the revised UK guidelines (issued in 2016) includes a section in which the evidence is disputed, referring to protective effects. It refers to the 'increased risk of a small number of cancer types' and states: "Different levels of alcohol consumption have a range of effects on cancer risk including no impact on the majority of cancers, and in some cases, an inverse relationship".[11] As well as misrepresenting the evidence, this statement is misleading as it confuses the number of different "types" of cancer, with the risk of specific cancers. This is discussed further below.

\section{Distraction: focussing discussion away from the independent effects of alcohol in increasing the risk of common cancers}

3(i) Minimising the role of alcohol by pointing to a wide range of other risk factors

A common strategy appears to involve discussing a wide range of real and potential risk factors, thus presenting alcohol as just one risk among many. Eight of the SAPROs appear to do this. A wide range of risk factors, including irrelevant and non-modifiable ones, are referred to, for example:

"Not all heavy drinkers get cancer, as multiple risk factors are involved in the development of cancers including genetics and family history of cancer, age, environmental factors, and behavioural variables, as well as social determinants of health".(Australia: Drinkwise[26]) 
"Alcohol has been identified as a known human carcinogen by IARC, along with over 1,000 others, including solvents and chemical compounds, certain drugs, viral infection, solar radiation from exposure to sunlight, and processed meat". (IARD [27])

"For example, the fact that you are female is a risk factor in developing breast cancer. We also know breast cancer is age-related so you're more likely to develop it as you get older and that you're more prone to breast cancer if it is part of your family history. These are all factors beyond our control. We also know that risk is related to the 'hormone environment' that women experience during the course of early pregnancy, child birth and breastfeeding which all exert a protective effect" (Drinkaware, UK[32])

In other cases, wider socioeconomic factors are also stated as possible causes by IARD[27], SABMiller[31] and the Portman Group.[11]

Such messages are misleading and potentially confusing. Misleading, because they emphasise potential moderating factors without acknowledging the clear independent risk of alcohol consumption; the information therefore may suggest to readers that only people with these co-factors are at risk. Confusing, because it is unclear how the consumer is meant to interpret them or what action s/he is meant to take (e.g., messages about increasing risk with age at beginning of menarche, or about wider socioeconomic factors).

Discussion of smoking may also be used in this way to distract from the independent effects of alcohol. The scientific evidence shows that the risk is indeed higher among smokers, $[7$ 8] and there is a strong interaction between alcohol and smoking for cancers of the upper aerodigestive tract.[8] The risk of cancer is also independent of smoking.[33] [10] [34] As for specific cancers, for breast cancer the risk does not appear to be confounded by smoking,[7] and the association is unclear for colorectal and pancreatic cancer.[8] Alcohol industry bodies in some cases appear to imply that it is mainly smokers who should be concerned. For example the Portman Group's response to the consultation on the new UK alcohol guidelines places considerable weight on smoking, recommending that it should 
be emphasised (see Supplementary Table S2). [11] An emphasis on smoking appears in other AI materials [27] (Supplementary Table S2).

3 (ii) Emphasising less common cancers, and emphasising cancer "types" rather than cancer prevalence

In a few cases alcohol organisations places an emphasis on less common cancers. The SABMiller website'TalkingAlcohol.com' appears to imply that alcohol is only associated with less common forms of breast cancer:

"Recent studies indicate that alcohol consumption may be more strongly linked to a certain less common form of breast cancer (lobular cancer), than it is to the most common type of breast cancer (ductal cancer)'”[31]

The evidence regarding lobular and ductal cancers is itself unclear. The Women's Health Initiative Observational study found that, compared with never-drinkers, women consuming 7+ alcoholic drinks per week had a slightly increased risk of hormone-receptor positive lobular cancer, than ductal cancer.[35] However the authors also concluded that alcohol was significantly positively associated with total breast cancer, with even a moderate amount of alcohol (>10 g/day) significantly increasing breast cancer risk. Other studies have not found that alcohol risk is clearly differentiated by subtype.[3] It is possible that the risk may be slightly greater for lobular than ductal tumours, though the direct relevance of this information for SABMiller's consumers is unclear.

The Portman Group document also appears to imply that the risk only applies to less common cancers, by conflating cancer type with cancer prevalence. It asserts that "the vast majority of cancer types are not associated with alcohol consumption", and criticises the revised UK guidelines on the grounds that they "amplify the small number of cancer types where increased risk is linked to alcohol 
consumption." [11] The small number of cancer "types" distracts from the fact that these include two of the most common cancers (breast and colorectal cancer).[1 2]

\section{Misrepresentation of the risks of breast and colorectal cancer}

There appear to be two particularly frequent areas of misinformation on these sites: breast cancer and colorectal cancer. In all, twenty-one of the organisations present no, or misleading information on breast cancer, and twenty-two present no information, or misleading information on colorectal cancer (Table 1). Some websites single out these cancers (but not others) to dispute or deny the increase in risk. This can be seen on the websites of Éduc'alcool (Quebec)[22] and on the Drinkwise (Australia) website.[26] One such example is Éduc'alcool's statement (above) that “no causal relationship has been shown between moderate drinking and breast cancer”. [36] The Wine in Moderation website includes a lengthy section on confounding in relation to the risk of breast cancer, concluding that "based on scientific evidence, in post menopausal women, the increase in the risk of breast cancer, if there is any at all, is small."[37] (our emphasis). The SAB Miller website also has a significant focus on proposing alternative risk factors for breast cancer, other than alcohol (see interview in Supplementary Table S2).[37] The Portman Group's response to the UK guidelines includes a section on breast cancer, in which the evidence is disputed. For example, it states that 'studies associating moderate alcohol consumption are contradictory". The IARD 'Drinking and NCDs" brochure wrongly links breast cancer only to heavy drinking.[38]

In the case of Drinkwise (Australia), an interactive tool (see: https://drinkwise.org.au/alcohol-andyour-health/\#app) includes clickable links to the immune system, heart, liver, skin, brain, liver, stomach, pancreas, bowel kidneys and reproductive system, but not the breast. Clicking on the "Liver" and "Bowel" links takes the user to other pages about cancers, but there is no similar link to information on breast cancer. 
Most of the websites/documents do not mention colorectal cancer, even when in some cases (e.g., Heineken, Drinkwise) they specifically mention other cancers. In one other case (Wine in Moderation) it is stated inaccurately that alcohol reduces the risk of colorectal cancer.[30] On the Australian Drinkwise website, colorectal cancer is mentioned in the list of cancers caused by alcohol, but not in the "Alcohol and your bowel" section, which discusses "bacterial overgrowth in your small intestine which may cause bloating, gas, abdominal pain, constipation and diarrhoea", and irritable bowel syndrome, but not cancer.[29] The information on colorectal cancer presented on two other websites appears to be accurate (Canada's Educ'alcool, and the IARD website).[27 37]

\section{References cited by SAPROs to substantiate their statements}

Six SAPRO websites substantiate their statements on cancer and alcohol by providing a list of references cited in the text, or a bibliography. Of the SAPROS which include references, IARD is most likely to cite peer-reviewed alcohol-cancer related publications (48), followed by ARA (16), and Drinkaware UK (12). However, this does not mean that the citations used are the most relevant. For example, independent IARC reports are rarely cited, and in disputing the evidence on increased breast cancer risk, the Portman Group document does not reference the IARC reviews, other systematic reviews, nor the Committee on Carcinogenicity review. The only cited academic review paper disputes the relationship between breast cancer and alcohol consumption, using many of the arguments discussed above.[39] The lead author of the paper is head of Scientific Affairs of the U.S. Distilled Spirits Council (DISCUS).

\section{Discussion}


Principal findings: Public awareness of the risk of cancer from alcohol consumption is low,[40] and it has been argued that greater public awareness, particularly of the risk of breast cancer, poses a significant threat to the alcohol industry.[20] Our analysis suggests that the major global alcohol producers may attempt to mitigate this risk by disseminating misleading information about cancer through their "responsible drinking" bodies. The existing evidence of strategies employed by the alcohol industry suggests that this may not be a matter of simple error.[41] [42] It is already known that the alcohol industry misrepresents scientific evidence, for example in relation to Minimum Unit Pricing (MUP) of alcohol,[43] where it has been demonstrated that the industry employs 'denialism' in public discussions.[43] Our analysis suggests that alcohol industry denialism extends to the relationship between alcohol and cancer.

Strengths and weaknesses of the study, and in relation to other studies: The main strength of the study is its breadth: it analyses all information about cancer provided by the major international CSR bodies which are used by the AI to disseminate information to the public. This strengthens the conclusion that the findings are both robust and generalisable. The main weakness is that there are many other mechanisms and organisations through which industry disseminates health-related information (e.g. through twitter accounts, at meetings, and via advertising campaigns) which we did not examine. It seems implausible however that industry would adopt different messaging regarding cancer through other outlets, though this is an important issue for further research.

There are no closely similar studies to this, though our findings have similarities with other alcohol industry strategies, particularly the focus on individual causal factors, and personal variability in risk, even where these are not relevant.[42] The systematic review by Savell et al. (2015) for example found that manipulation of evidence was a key alcohol strategy for influencing marketing regulations. This included selective citation of industry-favourable evidence, omission of evidence, removal of industry-troubling phrases, and contesting the nature of the evidence, all of which we found here.[42] 
The most obvious parallel is with the global tobacco industry's decades-long campaign to mislead the public about the risk of cancer, which also used front organisations and CSR activities to mislead the public.[44 45] The tobacco industry also developed arguments which emphasise the complex aetiology of lung cancer and CHD, in order to help deny the epidemiological evidence; for example it engaged in an ever-wider search for any factor, however unlikely (such as keeping pet birds, or inadequate consumption of green tea) that might serve as an independent risk factor for smokingrelated diseases.[46] The extensive alcohol industry discussions of potential confounders in the alcohol-cancer relationship may be seen in the same light. The analysis by Ulucanlar et al. (2014) of tobacco industry submissions to the public consultation on plain packaging found similar extensive misrepresentation of evidence, including distortion of the findings of scientific studies.[47]

One important finding is that AI materials appear to specifically omit or misrepresent the evidence on breast and colorectal cancer. One possible reason is that these are among the most common cancers, and therefore may be more well-known or salient than oral and oesophageal cancers (which we found to be more commonly acknowledged by industry SAPROs (Table 1)). The provision of misleading information about breast cancer may also reflect existing industry strategies aimed at developing the female alcohol market.[20] Note also that these data were collected in 2016. Some website content may therefore have changed since the data were collected.

Implications for clinicians and policymakers: Overall, through its provision of misleading information the AI can maintain 'the illusion of righteousness' in the eyes of policymakers,[48] while negating any significant impact on consumption and profits. These findings therefore have significant implications. They provide evidence that the alcohol industry, like the tobacco industry, misleads the public and policymakers about the cancer risks of their products. Our findings are also a reminder of the risk which accompanies giving to the AI the responsibility of informing the public about alcohol and health.[49] 
The findings also suggest that major international alcohol companies may be misleading their shareholders about the risks of their products. This may leave the industry open to litigation in some countries, as has happened with the tobacco and, more recently, other industries. For example, CocaCola and the American Beverage Association are currently being sued for downplaying the risks of their products.[50]

Finally, many public health bodies, academics and practitioners liaise with the industry bodies included in this study, for example by acting as advisors or trustees, or by collaborating with them in research or implementation activities. Despite their undoubtedly good intentions, we suggest that it is unethical for them to lend their expertise and legitimacy to industry campaigns which aim to mislead the public about alcohol-related harms.

\section{Areas for further research}

Further analysis of citation bias is needed, as cherry-picking of evidence sources appears common (e.g., single studies, and magazine and newspaper articles frequently appear to be cited in preference to up-to-date systematic reviews). The analysis of information produced by new alcohol industry bodies which disseminate information about alcohol and health- such as the newly-established Alcohol Information Partnership (AIP)[51] - should also be carefully monitored. There is also an urgent need to examine other industry websites, documents, social media and other materials in order to assess the nature and extent of the distortion of evidence, and whether it extends to other health information- for example, in relation to cardiovascular disease. Comparative research across industries and with other areas of alcohol policy to examine industry distortion of evidence is also needed.

\section{Conclusion}


It has often been assumed that, by and large, the AI, unlike the tobacco industry, has tended not to deny the harms of alcohol.[52] Our analysis shows that, on the contrary, the global alcohol industry is currently actively disseminating misinformation about alcohol and cancer risk, particularly breast cancer.[48] The alcohol industry, unlike the tobacco industry, still has significant access in many countries to government health departments.[52 53] It is also active in the international policy arena, with, for example, partner or stakeholder status at WHO and UN meetings relevant to alcohol, on occasions when the tobacco industry is excluded.[52] This study shows that the alcohol industry uses similar tactics to the tobacco industry, to the same ends: to protect its profits, to the detriment of public health. The full scale and nature of these activities requires urgent investigation.

Acknowledgements: Anonymised.

Funding: This study had no specific funding. 


\section{References}

1. Rehm J, Mathers C, Popova S, Thavorncharoensap M, Teerawattananon Y, Patra J. Alcohol and Global Health: Global burden of disease and injury and economic cost attributable to alcohol use and alcohol-use disorders. Lancet 2009;373:2223-33

2. Cancer Research UK: Statistics on preventable cancers. Available at: http://www.cancerresearchuk.org/health-professional/cancer-statistics/risk/preventablecancers\#heading-Zero. Accessed 3rd march 2017.

3. IARC Monographs on the evaluation of carcinogenic risks to humans, Volume 44, 1988. Available at: http://monographs.iarc.fr/ENG/Monographs/vol44/index.php. Accessed 19th February 2017.

4. Baan R. Carcinogenicity of alcoholic beverages. Lancet Oncology 2007;8(4):292-93

5. Boyle P, Boffeta P, Lowenfels A, et al. Alcohol: science, policy and public health. Oxford: Oxford University Press, 2013.

6. Shield K, Soerjomataram I, Rehm J. Alcohol Use and Breast Cancer: A Critical Review. Alcoholism: Clinical and Experimental Research 2016;40(6):1166-81

7. IARC. Personal habits and indoor combustions. IARC Monographs on the evaluation of carcinogenic risks to humans. Lyon, France. 2012

8. Committee on Carcinogenicity of chemicals in food, consumer products and the environment (COC). Statement 2015/S2. Available at: https://www.gov.uk/government/publications/consumption-of-alcoholic-beverages-andrisk-of-cancer. Accessed 31st August 2016

9. Zhao J, Stockwell T, Roemer A, Chikritzhs T. Is alcohol consumption a risk factor for prostate cancer? A systematic review and meta-analysis. BMC Cancer 2016;16:845

10. UK Chief Medical Officers' Alcohol Guidelines Review: Summary of the proposed new guidelines. See: https://www.gov.uk/government/uploads/system/uploads/attachment data/file/489795/s ummary.pdf. Accessed 24th December 2016.

11. Portman response to consultation. Response Document No. 11., pp76-108 See: https://www.gov.uk/government/consultations/health-risks-from-alcohol-new-guidelines. Accessed 24th December 2016.

12. Babor T, Robaina K. Public health, academic medicine, and the alcohol industry's corporate social responsibility activities. Am J Public Health 2013;103(2):206-14

13. Global alcohol producers' committments. http://www.producerscommitments.org/. Accessed 12th February 2016.

14. Beer, Wine and Spirits Producers' Commitments to Reduce Harmful Drinking. 2015 Progress Report: See: http://www.producerscommitments.org/wp-content/uploads/2016/07/2015Progress-Report.pdf. Accessed 4th January 2016.

15. Foster N. Qualitative Methods in Organisational Research. A Practical Guide. London: Sage, 1994.

16. Hawkins B, Holden C. Framing the alcohol policy debate : industry actors and the regulation of the UK beverage alcohol market. Critical Policy Studies 2013;7(1):37-41

17. Pope C, Ziebland S, Mays N. Qualitative research in health care. Analysing qualitative data. British Medical Journal 2000;320:114-6

18. Ritchie J, Spencer L. Qualitative data analysis for applied policy research. In: Bryman A, Burgess R, eds. Analysing qualitative data. Oxford: Routledge, 1994.

19. Forster N. The analysis of company documentation. In: Cassell C, Symon G, eds. Qualitative methods in organizational research: a practical guide. London: Sage, 1994. 
20. Connor J. Alcohol consumption as a cause of cancer. Addiction 2016:Jul 21. doi: 10.1111/add.13477. [Epub ahead of print]

21. International Alliance for Responsible Drinking (IARD, formerly ICAP). Available at: http://www.iard.org/. Accessed 23rd December 2016.

22. Éduc'alcool. Quebec SAPRO led by industry, also involving public bodies, e.g. Quebec College of Physicians, Minsitry of Education. See: http://educalcool.qc.ca/en/. Accessed 23rd December 2016.

23. Alcohol may be a cause of some types of cancer. SAB Miller website talkingalcohol. Available at: http://www.talkingalcohol.com/index.asp?pageid=54. Accessed 30th August 2016.

24. Pernod Ricard Wise Drinking Brochure (App also available). See: http://pernodricard.com/files/fichiers/Presse/Documents/PR CSR Brochure EN.pdf. Accessed 23rd december 2016.

25. DrinkIQ, Diageo website: Alcohol's effect on your body. See: https://www.drinkiq.com/en$\mathrm{gb} /$ how-alcohol-affects-us/the-body/alcohols-effect-on-your-body/. Accessed 23rd December 2016.

26. Drinkwise: Is your drinking putting you at risk of cancer?. See: https://drinkwise.org.au/drinkingand-you/is-your-drinking-putting-you-at-risk-of-cancer/\# Accessed 23rd December 2016.

27. IARD: Drinking and cancer: See: http://www.iard.org/wp-content/uploads/2016/02/HRCancer.pdf. Accessed 23rd December 2016.

28. Wine Information Council http://www.wineinformationcouncil.eu/. Accessed 28th June 2017.

29. ARA: Industry Association for responsible alcohol use. Cancer and alcohol. See: http://www.ara.co.za/cancer--alcohol/. Accessed 24th January 2017.

30. Wine in Moderation programme. Available at: http://www.wineinmoderation.eu/. Accessed 23rd December 2016.

31. SAB Miller. TalkingAlcohol.com. Alcohol and your body: cancer. See: http://www.talkingalcohol.com/index.asp?pageid=54. Accessed 23rd December 2016.

32. Drinkaware UK. Alcohol and breast cancer. See: https://www.drinkaware.co.uk/alcoholfacts/health-effects-of-alcohol/diseases/alcohol-and-breast-cancer/. Accessed 24th December 2016.

33. NHS Choices: Breast cancer (female) - Causes. See: http://www.nhs.uk/Conditions/Cancer-ofthe-breast-female/Pages/Causes.aspx. Accessed 24th December 2016.

34. Cancer Research UK. Alcohol facts and evidence. See: http://www.cancerresearchuk.org/aboutcancer/causes-of-cancer/alcohol-and-cancer/alcohol-facts-and-evidence. Accessed 24th December 2016.

35. Lew J, Freedman N, Leitzmann M, et al. Alcohol and risk of breast cancer by histologic type and hormone receptor status in postmenopausal women: the NIH-AARP Diet and Health Study. Am J Epidemiol 2009;170(3):308-17

36. Éduc'alcool (Canada). Moderate drinking and breast cancer risk. Available at: http://educalcool.qc.ca/en/alcohol-and-you/health/the-effects-of-moderate-regularalcohol-consumption/2/\#.WIDpG7Gcb-Y. Accessed 24th January 2017.

37. Wine in Moderation: who we are: Available at: http://www.wineinmoderation.eu/en/content/Who-we-are.16/. Accessed 24th January 2017.

38. Drinking and NCDs. IARD (International ALliance for | Responsible Drinking) Health Review. Available at: http://www.iard.org/wp-content/uploads/2016/06/HR-NCDs.pdf. Accessed 26th July 2016.

39. Zakhari S, Hoek J. Alcohol and Breast Cancer: Reconciling Epidemiological and Molecular Data. In: Vasiliou V, Zakhari S, Seitz H, Hoek J, eds. Biological Basis of Alcohol-Induced Cancer. Advances in Experimental Medicine and Biology, vol 815. Cham, Switzerland: Springer, 2015. 
40. Buykx P, Li J, Gavens L, et al. Public awareness of the link between alcohol and cancer in England in 2015: a population-based survey. BMC Public Health 2016;16:1194

41. McCambridge J, Hawkins B, Holden C. Industry use of evidence to influence alcohol policy: a case study of submissions to the 2008 Scottish Government Consultation. PLOS Med 2013;10(4):e1001431

42. Savell E, Fooks G, Gilmore A. How does the alcohol industry attempt to influence marketing regulations? A systematic review. Addiction 2015;111(1):18-32

43. Katikireddi S, Hilton S. How did policy actors use mass media to influence the Scottish alcohol minimum unit pricing debate? Comparative analysis of newspapers, evidence submissions and interviews. Drugs: Education, Prevention and Policy 2015;22(2):125-34

44. Neuman M, Bitton A, Glantz S. Tobacco industry strategies for influencing European Community tobacco advertising legislation. Lancet 2002;359(9314):1323-30

45. Gilmore A, Fooks G, Drope J, Bialous S, Jackson R. Exposing and addressing tobacco industry conduct in low-income and middle-income countries. Lancet 2015;385(9972):1029-43

46. Petticrew M, Lee K. The "Father of Stress" Meets "Big Tobacco": Hans Selye and the Tobacco Industry. Am J Public Health 2011;101(3):411-18

47. Ulucanlar S, Fooks G, Hatchard J, Gilmore A. Representation and Misrepresentation of Scientific Evidence in Contemporary Tobacco Regulation: A Review of Tobacco Industry Submissions to the UK Government Consultation on Standardised Packaging. Plos Med DOI:

10.1371/journal.pmed.1001629 2014;11(3)

48. Yoon S, Lam T-H. The illusion of righteousness: corporate social responsibility practices of the alcohol industry. BMC Public Health;13:630 www.biomedcentral.com/1471-2458/13/630

49. Monteiro $M$, Babor $T$, Jernigan $D$, Brookes $C$. Alcohol marketing regulation: from research to public policy. Addiction 2017;112 Suppl 1:3-6

50. Reuters Health News: Lawsuit in U.S. says Coca-Cola downplays risks of sugary drinks. See: http://uk.reuters.com/article/us-coca-cola-lawsuit-idUKKBN14O24T. Accessed 5th January 2017.

51. Alcohol Information Partnership. See: http://alcoholinfopartnership.co.uk/. Accessed 4th January 2017.

52. Casswell S. Vested interests in addiction research and policy. Why do we not see the corporate interests of the alcohol industry as clearly as we see those of the tobacco industry? Addiction 2013;108:680-85

53. Hawkins B, Holden C, Eckhardt J, Lee K. Reassessing policy paradigms: A comparison of the global tobacco and alcohol industries. Global Public Health 2016:http://dx.doi.org/10.1080/17441692.2016.1161815

54. DISCUS: Distilled Spirits Council of the United States. See: http://www.discus.org/responsibility/ and http://www.drinkinmoderation.org/ Accessed 23rd December 2016.

55. Brewers of Europe, Beer Wisdom website. See: http://www.beerwisdom.eu/. Accessed 23rd December 2016.

56. Jacob's Creek The Wine Line - Drink Responsibly. http://www.jacobscreek.com/uk/aboutus/drink-responsibly. Accessed 23rd December 2016. 


\section{Key to tables}

Table 1: Tactics used by alcohol industry SAPROs and other organisations

Supplementary Table 1: Summary of IARC review (2012), and UK Committee on Carcinogenicity review (2016)

Supplementary Table 2: Advice related to cancer disseminated by Alcohol industry SAPROs (Social Aspects and Public Relations Organizations) via websites and other documents

Supplementary Table 3: Additional examples of misleading/false statements about alcohol and cancer 
Petticrew M, Maani Hessari N, Knai C, Weiderpass E. How alcohol industry organisations mislead the public about alcohol and cancer. Drug and Alcohol Review (March 2018), 37, 293-303

DOI: $10.1111 /$ dar. 12596 


\title{
Supplementary Table 3: Additional examples of misleading/false statements about alcohol and cancer
}

\author{
Denying, disputing, or selectively ignoring the relationship between alcohol consumption and \\ cancer, or selected cancers \\ Educ'alcool (Canada): "There is no proven causal link or even association between low alcohol consumption and colorectal cancer." \\ US DISCUS: No mention of cancer, only mentions putative beneficial effects: "Studies show it is the ethanol (alcohol) in all types of \\ beverage alcohol - distilled spirits, beer or wine - that, when consumed in moderation, is associated with a lower risk of cardiovascular \\ disease..."
}

Heineken: Only breast and oesophageal cancer mentioned; other cancers omitted: "There is a relationship between alcohol and certain types of cancer. For instance a higher risk of breast cancer and oesphageal cancer is correlated with drinking alcohol and the risks increase with increased consumption."

Foundation for Advancing Alcohol Responsibility (Responsibility.org): Only mentions drink driving.

Beer Wisdom: Brewers of Europe: Focusses only on pregnancy, drink driving, underage drinking

Drinkaware, UK: "Light to moderate drinking is associated with minimally increased risk of overall cancer... For men who have never smoked, risk of alcohol related cancers is not appreciably increased for light and moderate drinking (up to two drinks per day)".

IARD: "Recent research suggests that light to moderate drinking is not significantly associated with an increased risk for total cancer in either men or women"

IARD: "In general, more frequent and heavier drinking is associated with greater risk of developing cancers of the oral cavity, larynx, pharynx, and esophagus; cancer of the female breast; liver cancer and colorectal cancer" (Inaccurate representations of the dose response relationships)

ICAP: "Some people who drink heavily also develop certain types of cancers, in particular of the mouth and throat".

Wine in Moderation: "In summary, the cancer risk should not be evaluated in isolation, one particular food factor (like wine consumption) should not be analysed out of context with its cultural and culinary habits... The effect of wine on cancer risk also depends on whether it is consumed with or without a meal and the nature of other foods consumed. There needs to be a distinction between different types of cancer and the influence of lifestyle (according to the World Cancer Research Fund, more than 1/3 of the cancers could be prevented by a healthy diet, regular physical activity and no weight gain) and genetic factors needs to be assessed". [Note: the quote does not clarify that the "1/3 of cancers" includes those prevented by not drinking]

Portman Group (UK): "Different levels of alcohol consumption have a range of effects on cancer risk including no impact on the majority of cancers, and in some cases, an inverse relationship."

Carlsberg, Responsible Drinking: "Drinking too much alcohol over a long period of time can raise blood pressure and heavy drinkers have a higher risk of liver disease, strokes and cancers of the mouth and throat."

\section{Erroneously stating or implying that risk only applies to particular patterns of drinking (in particular, heavy drinking, or binge drinking)}

Beer Wisdom: Brewers of Europe: Focusses only on "excessive alcohol consumption", rather than on health effects of moderate consumption; also pregnancy, drink driving, underage drinking]

IARD: Key point on first page of website: "Cancer risk associated with the consumption of alcohol is related to patterns of drinking particularly with heavy drinking over extended periods of time"

ICAP: The negative long-term effects of alcohol are mostly associated with heavy drinking over long periods of time. People who drink excessively have an increased risk of becoming alcohol-dependent. Heavy drinking may also result in brain damage and harm to the liver, as discussed above.

Wine in Moderation: "There is evidence that excessive consumption of alcoholic beverages or binge drinking is associated with increased morbidity and mortality from several forms of cancer".

Wine in Moderation: "Low amounts of wine on the other hand, are not associated with the risk of any cancer site with the possible exception of breast cancer for women and cancers of upper gastrointestinal tract (GIT) such as the mouth and throat as well as the liver." 
Carlsberg, Responsible Drinking: "Drinking too much alcohol over a long period of time can raise blood pressure and heavy drinkers have a higher risk of liver disease, strokes and cancers of the mouth and throat."

\section{Wrongly claiming that the risk primarily applies to particular subgroups (in particular, smokers), rather than the general population}

Diageo, DrinkIQ: "In the long term: Scientific research has shown a variety of long term effects from low to moderate consumption of alcohol - some positive and some negative. What is clear is that it is complicated and specific to individuals - and best discussed by individuals with their GP or healthcare provider".

Portman Group (UK): Furthermore, international evidence demonstrates that the risk of certain alcohol-related cancers increases considerably with tobacco use. This association has not been presented in the proposed guidelines, but would clearly inform consumers that the relative low risk of some cancers from moderate alcohol consumption increases significantly if they also smoke.

\section{Minimising the role of alcohol by pointing to a wide range of other risk factors}

Drinkwise, Australia: The likelihood of developing breast cancer is impacted upon by how much you drink over your lifetime, as well as other risk factors for the disease such as lifestyle, family history, medical history, reproductive history, hormone replacement therapy, obesity and exposure to cancer-causing compounds or carcinogens". [Note: these are not mentioned for other cancers]

Drinkwise, Australia: "Not all heavy drinkers get cancer as multiple risk factors are involved in the development of cancers including genetics and family history of cancer, age, environmental factors, and behavioural variables, as well as social determinants of health"

IARD: "Multiple risk factors are involved in the development of cancers and include genetics and family history of cancer, age, environmental factors, and performance variables, as well as social determinants of health."

IARD: "Alcohol has been identified as a known human carcinogen by IARC, along with over 1,000 others, including solvents and chemical compounds, certain drugs, viral infection, solar radiation from exposure to sunlight, and processed meat".

IARD: Includes a methodological section on how confounding may obscure relationships, Also "Social determinants are a key potential confounder when it comes to assessing the impact of drinking on cancer risk, and pose a particular challenge when addressing those

living in poverty and marginalized populations."

Drinkaware, UK: "The fact that you are female is a risk factor in developing breast cancer. We also know breast cancer is age-related so you're more likely to develop it as you get older and that you're more prone to breast cancer if it is part of your family history. These are all factors beyond our control... We also know that risk is related to the 'hormone environment' that women experience during the course of early pregnancy, child birth and breastfeeding which all exert a protective effect.... Seen in relation to all of these other factors, excessive alcohol consumption appears to contribute about $6 \%$ of the overall risk of breast cancer in developed countries."

Portman Group, UK: Cancer Research UK have shown, for example, that significantly fewer cases of breast cancer occur among women from lower socio-economic groups - perhaps due to factors such as prevalence of breast screenings and earlier first pregnancy. Overall common lifestyle factors are considered as a cause in $27 \%$ of breast cancer cases: being overweight accounts for $9 \%$ of all cases, alcohol $6 \%$, night-shift working 5\%, GRT 3\%, lack of physical activity $3 \%$ and oral contraception $1 \%$.

\section{Claiming that the mechanism is not known, and/or that there is a lack of consensus and so the evidence of a causal relationship is not trustworthy}

IARD: "Recent studies indicate a dose-response relationship between alcohol consumption and breast cancer, although this relationship was not evident in some past studies".

Wine in Moderation: "With regards to breast cancer and alcoholic beverages, the research results vary widely since not only the amount of alcohol but also other co-factors as well as drinking pattern play an important role and have to be taken into consideration"

Wine in Moderation: "All the studies show that the knowledge about the causes of breast cancer is still very incomplete and as scientists from the National Institute on Alcohol Abuse and Alcoholism in the USA, recently pointed out, some other (possible confounding) factors have not been considered in the research relating the consumption of alcoholic beverages to breast cancer..."(website then goes on to list arguments against epidemiological studies- see Appendix 2).

SABMiller: "Although alcohol is a well-established risk factor for breast cancer, the mechanism by which alcohol consumption may cause breast cancer is not fully known. The relationship between alcohol consumption and breast cancer is undergoing vigorous research". 


\section{Pointing to protective effects of some cancers to confuse the picture of overall risk}

Wine in Moderation: Epidemiological studies indicate a lower cancer risk for wine drinkers for most cancer sites compared to drinkers of other alcoholic beverages. Moderate wine intake may actually reduce the risk of oesophagus, thyroid, lung, kidney and colorectal cancers as well as Non-Hodgkin's Lymphoma....Concerning breast cancer, there may also be a protective role for wine.

Portman Group (UK): "Different levels of alcohol consumption have a range of effects on cancer risk including no impact on the majority of cancers, and in some cases, an inverse relationship."

\section{Misrepresentation, or obfuscation of the risks of breast, and colorectal cancer}

Educ'alcool (Canada): Some studies show a link between alcohol and breast cancer among both pre-menopausal and post-menopausal women. However, no causal relationship has been shown between moderate drinking and breast cancer."

Heineken: Colorectal cancer not mentioned: "There is a relationship between alcohol and certain types of cancer. For instance a higher risk of breast cancer and oesphageal cancer is correlated with drinking alcohol and the risks increase with increased consumption."

Drinkwise, Australia: The likelihood of developing breast cancer is impacted upon by how much you drink over your lifetime, as well as other risk factors for the disease such as lifestyle, family history, medical history, reproductive history, hormone replacement therapy, obesity and exposure to cancer-causing compounds or carcinogens". [Note: these are not mentioned for other cancers]

Drinkwise, Australia: Interactive tool for women has clickable links for immune system, heart, liver, skin, brain, liver, stomach, pancreas, bowel kidneys and reproductive system, not breast. Clicking on Liver and bowel highlights links to page about cancers. No breast link provided.

IARD: Section on female breast cancer. Alcohol is presented at the end of a long list of other potential risk factors: "Breast cancer is the leading cancer among women, and is associated with a large number of individual risk factors. Research has shown that breast cancer risk is associated with family history and hormonal and reproductive factors. Increased risk has been reported with hormone replacement therapy, but varies by the type of breast cancer (ductal, lobular, or mixed). Similarly, risk associated with other reproductive factors, such as age at menarche or breastfeeding, have been shown to differ by cancer subtypes. According to IARC, cancer of the female breast is causally associated with the consumption of alcohol beverages.

IARD: "Some evidence suggests that at moderate or high levels of alcohol consumption, adequate intake of the amino acid folate may attenuate the risk for breast cancer"

IARD: Among men, an increase was observed only among men who were also smokers. For them, the increase in risk was primarily due to colorectal cancer.

Wine in Moderation: "An increased breast cancer risk is observed in women with additional co-factors such as genetic disposition, hormone replacement therapy (HRT), low folate intake, overweight and smoking....A meta-analysis for example, examined the influence of hormones on breast cancer risk and found that alcoholic beverages $(>20 \mathrm{~g} / \mathrm{d}$ ) might increase the breast cancer risk only among women who were concurrently using menopausal hormone therapy (HT) and /or having estrogen receptors positive tumors. These findings indicate that a hormone-related mechanism may mediate the relation between alcohol drinking and an increased breast cancer risk. Among women who had ceased using $\mathrm{HT}$, the risk associated with 2 or more drinks per day was not apparent. Another factor to be considered is folate intake. Several studies have shown an inverse relation between folate intake and cancer. Accordingly, some research results found a significant interaction between the consumption of alcoholic beverages and folate intake where alcoho seems to increase the risk significantly only for those individuals with low folate intake. \{Misleading, because there is also an independent effect] 
Petticrew M, Maani Hessari N, Knai C, Weiderpass E. How alcohol industry organisations mislead

the public about alcohol and cancer. Drug and Alcohol Review (March 2018), 37, 293-303

DOI: $10.1111 /$ dar. 12596

Table 1: Tactics used by Alcohol industry Social Aspects and Public Relations Organisations (SAPROs), and other organisations

\begin{tabular}{|c|c|c|c|c|c|c|c|c|}
\hline $\begin{array}{l}\text { SAPRO, or other alcohol- } \\
\text { industry-related body }\end{array}$ & $\begin{array}{l}\text { Selective } \\
\text { omission of } \\
\text { cancer risk, } \\
\text { or specific } \\
\text { cancers (e.g. } \\
\text { breast) }\end{array}$ & $\begin{array}{l}\text { Denies } \\
\text { alcohol } \\
\text { causes at least } \\
\text { one type of } \\
\text { cancer }\end{array}$ & $\begin{array}{l}\text { Claims that } \\
\text { risk only } \\
\text { applies to } \\
\text { particular } \\
\text { drinking } \\
\text { patterns }\end{array}$ & $\begin{array}{l}\text { Confusing } \\
\text { the } \\
\text { relationship } \\
\text { using range } \\
\text { of other risk } \\
\text { factors }\end{array}$ & $\begin{array}{l}\text { Pointing to } \\
\text { complexity } \\
\text { to suggest } \\
\text { little } \\
\text { evidence of } \\
\text { risk }\end{array}$ & $\begin{array}{l}\text { Claiming that } \\
\text { mechanism } \\
\text { not known to } \\
\text { undermine } \\
\text { evidence of } \\
\text { risk }\end{array}$ & $\begin{array}{l}\text { Discussion } \\
\text { of breast } \\
\text { cancer? }\end{array}$ & $\begin{array}{l}\text { Discussion } \\
\text { of } \\
\text { colorectal } \\
\text { cancer? }\end{array}$ \\
\hline $\begin{array}{l}\text { 1. ARA (South African industry } \\
\text { SAPRO) }\end{array}$ & & & & & & & Yes & Yes \\
\hline 2. Pernod Ricard "Wise Drinking" & $\mathbf{X}$ & & & & & & No & No \\
\hline 3. CANADA: Éduc'alcool & $\mathbf{X}$ & $\mathbf{X}$ & & & $\mathbf{X}$ & & $\begin{array}{l}\text { Yes, but } \\
\text { inaccurate }\end{array}$ & Yes \\
\hline $\begin{array}{l}\text { 4. US: DISCUS "Distilled Spirits } \\
\text { Council of the United States"[54] }\end{array}$ & $\mathbf{X}$ & & & & & & No & No \\
\hline $\begin{array}{l}\text { 5. Heineken website } \\
\text { Heinken.com }\end{array}$ & $\mathbf{X}$ & & & & & & $\begin{array}{l}\text { Yes - } \\
\text { mentioned }\end{array}$ & No \\
\hline $\begin{array}{l}\text { 6. Foundation for Advancing Alcohol } \\
\text { Responsibility (Responsibility.org) }\end{array}$ & $\mathbf{X}$ & & & & & & No & No \\
\hline $\begin{array}{l}\text { 7. Beer Wisdom: Brewers of Europe } \\
\text { http://www.beerwisdom.eu/[55] }\end{array}$ & $\mathbf{X}$ & & $\mathbf{X}$ & & & & No & No \\
\hline 8. Drinkaware.ie & & & & & & & Yes & Yes \\
\hline $\begin{array}{l}\text { 9. Ireland: MEAS: Mature Enjoyment of } \\
\text { Alcohol in Society http://www.meas.ie/ }\end{array}$ & $\mathbf{X}$ & & & & & & No & No \\
\hline 10. Australia: Drinkwise & $\mathbf{X}$ & & $\mathbf{X}$ & $\mathbf{X}$ & & & Yes & No \\
\hline $\begin{array}{l}\text { 11. Australia: The Wine Line (Jacobs } \\
\text { Creek wines)[56] }\end{array}$ & $\mathbf{X}$ & & $\mathbf{X}$ & & & & No & No \\
\hline 12. UK: Drinkaware & & & $\mathbf{X}$ & $\mathbf{X}$ & $\mathbf{X}$ & & Yes & Yes \\
\hline 13. IARD (formerly ICAP) & & $\mathbf{X}$ & $\mathbf{X}$ & $\mathbf{X}$ & & $\mathbf{X}$ & $\begin{array}{l}\text { Yes, but } \\
\text { inaccurate }\end{array}$ & Yes \\
\hline 14. ICAP & $\mathbf{X}$ & & $\mathbf{X}$ & & & & No & No \\
\hline $\begin{array}{l}\text { 15. Spirits Europe/ European Forum for } \\
\text { Responsible Drinking }\end{array}$ & $\mathbf{X}$ & & & & & & No & No \\
\hline
\end{tabular}


Petticrew M, Maani Hessari N, Knai C, Weiderpass E. How alcohol industry organisations mislead

the public about alcohol and cancer. Drug and Alcohol Review (March 2018), 37, 293-303

DOI: $10.1111 /$ dar. 12596

\begin{tabular}{|c|c|c|c|c|c|c|c|c|}
\hline $\begin{array}{l}\text { 16. Www.responsibledrinking.org } \\
\text { (IARD education site) }\end{array}$ & & & $\mathbf{X}$ & $\mathbf{X}$ & & & $\begin{array}{l}\text { Yes, but } \\
\text { misleading }\end{array}$ & No \\
\hline 17. Diageo: DrinkIQ.com [25] & $\mathbf{X}$ & & $\mathbf{X}$ & $\mathbf{X}$ & $\mathbf{X}$ & & $\begin{array}{l}\text { Yes, may be } \\
\text { misleading re: } \\
\text { "moderate" } \\
\text { drinking }\end{array}$ & No \\
\hline $\begin{array}{l}\text { 18. Wine in Moderation } \\
\text { (http://www.wineinmoderation.eu/) } \\
\text { includes the Wine Information Council; } \\
\text { members include Moet Hennessy, } \\
\text { Pernod Ricard }\end{array}$ & & $\mathbf{X}$ & $\mathbf{X}$ & $\mathbf{X}$ & $\mathbf{X}$ & $\mathbf{X}$ & $\begin{array}{l}\text { Yes, but } \\
\text { misleading }\end{array}$ & $\begin{array}{l}\text { No clear } \\
\text { statement }\end{array}$ \\
\hline 19. SABMiller: Talkingalcohol.com & & $\mathbf{X}$ & $\mathbf{X}$ & $\mathbf{X}$ & $\mathbf{X}$ & $\mathbf{X}$ & $\begin{array}{l}\text { Yes, but } \\
\text { misleading }\end{array}$ & $\begin{array}{l}\text { Yes, but } \\
\text { misleading }\end{array}$ \\
\hline $\begin{array}{l}\text { 20. Portman group response to new } \\
\text { alcohol guidelines, } 2016\end{array}$ & & $\mathbf{X}$ & $\mathbf{X}$ & $\mathbf{X}$ & $\mathbf{X}$ & & Yes & No \\
\hline $\begin{array}{l}\text { 21. Carlsberg "Responsible Drinking"; } \\
\text { CSR report } 2014\end{array}$ & $\mathbf{X}$ & & $\mathbf{X}$ & & & & No & No \\
\hline $\begin{array}{l}22-26 \\
\text { Bacardi } \\
\text { https://www.bacardilimited.com/corpora } \\
\text { te-responsibility/; } \\
\text { Asahi http://uk.asahibeer.co.uk/Alcohol- } \\
\text { Responsibility; . } \\
\text { Kirin } \\
\text { http://www.kirinichiban.com/; } \\
\text { Molson Coors } \\
\text { http://www.molsoncoors.com/en/respon } \\
\text { sibility/alcohol\%20responsibility; } \\
\text { Brown-Forman } \\
\text { https://www.brown- } \\
\text { forman.com/alcohol-responsibility/ }\end{array}$ & $\begin{array}{l}\text { No mention of } \\
\text { cancer }\end{array}$ & & & & & & No & No \\
\hline 27. Beam Suntory No access & & & & & & & No & No \\
\hline
\end{tabular}

